\title{
Mechanical Properties of Unidirectional Strand Board (USB) with Flat Vertical Density Profile
}

\author{
Costel Barbuta ${ }^{1}$, Pierre Blanchet ${ }^{1} \&$ Alain Cloutier $^{2}$ \\ ${ }^{1}$ Secondary Manufacturing, FPInnovations, Canada \\ ${ }^{2}$ Wood Research Center, Université Laval, Canada \\ Correspondence: Pierre Blanchet, Secondary Manufacturing, FPInnovations, Canada. E-mail: \\ pierre.blanchet@fpinnovations.ca
}

Received: March 20, 2012

Accepted: April 10, 2012 Online Published: June 5, 2012

doi:10.5539/jmsr.v1n3p42

URL: http://dx.doi.org/10.5539/jmsr.vln3p42

\begin{abstract}
This study investigated the effect of the relative humidity (RH) and density of unidirectional strand board (USB) on parallel, perpendicular and through-the-thickness elastic modulus $\left(E_{1}, E_{2}\right.$ and $\left.E_{3}\right)$ and interlaminar shear modulus $\left(\mathrm{G}_{13}\right.$ and $\left.\mathrm{G}_{23}\right)$. The relationships between these parameters and density were determined on unidirectional OSB panels with a flat density profile. The target densities were: 550,700 and $850 \mathrm{~kg} / \mathrm{m}^{3}$. Two $\mathrm{RH}$ levels at a constant temperature of $20^{\circ} \mathrm{C}$ were used to determine relationships between USB mechanical properties and moisture content (MC). The analysis of variance (ANOVA) indicated that only density had a significant effect on the mechanical properties considered. Even though the effect of RH was not significant, a trend could be observed. Unidirectional strand board $E_{1}, E_{2}, E_{3}, G_{13}$ and $G_{23}$, increased with an increase in density and decreased with an increase in RH. Finally, a regression procedure was used to determine the linear or quadratic equation necessary to predict the mechanical properties of the USB panels as a function of density. A positive correlation was observed between the unidirectional USB properties considered and density. These data will support the modeling of the hygromechanical behaviour of the USB used as component in wood composite constructions.
\end{abstract}

Keywords: OSB (oriented strand board), elastic modulus, shear modulus, panel density, moisture content

\section{Introduction}

Since its introduction in the building construction market in the 1980s, oriented strand board (OSB) has continued to replace plywood in several applications. OSB is widely used in residential and commercial buildings for wall and roof sheathing, flooring and I-joists. OSB is also used in other applications such as furniture, reels, pallets and boxes, trailer liners and recreational vehicle flooring (Hiziroglu, 2006). Even though OSB is already extensively used, the potential for this type of engineered wood-based panel in other applications is great. Blanchet (2008) tested the potential of OSB as a substrate in engineered wood flooring (EWF). The comparative study with Russian Baltic birch (Betula pendula Roth.) plywood (BBP) and high-density fibreboard (HDF) showed that EWF made with an OSB substrate suffered a higher level of cupping deformation. Blanchet (2008) suggested increasing the bending modulus of elasticity (MOE) of the OSB substrate in the parallel direction in order to obtain a performance comparable to that of the Russian BBP for this application. Barbuta et al. (2011) developed a specialty OSB with high MOE in the direction parallel to the strands as a substitute for plywood widely used as a substrate for EWF. Tests conducted in a conditioning room showed that specialty OSB made from a mixture of 90\% aspen (Populus tremuloides Michx.) and 10\% paper birch (Betula papyrifera Marsh.) offered a performance level similar to that of Russian BBP.

With increasing applications of OSB, modeling and simulation are required to predict the behaviour of the OSB construction under loading or variable relative humidity $(\mathrm{RH})$. The finite element method is a powerful tool to predict the behaviour of engineered wood-based composites. However, this method requires the physical and mechanical properties of each component. Due to the nature of OSB, its properties are mainly a function of density, mass ratio between surface layers and core layer, and moisture content (MC).

The vertical density profile (VDP) in the wood-based panels was identified as one of the major factors affecting board properties (Kelly, 1977; Xu \& Winistorfer, 1996). VDP describes density distributions through the 
thickness of the panel. The VDP shape affects almost every physical and mechanical property of OSB panels (Jin et al., 2009). The VDP shape is the result of a complex interaction between the main production parameters: initial MC mat gradient, internal mat strand properties, temperature of the hot press, hygrothermal response of the mat and press closure rate (Kelly, 1977; Andrews et al., 2001; Lee et al., 2006; Wang et al., 2000). Different studies predicted the properties of OSB on the basis of its layer properties, which are essentially defined by the VDP (Geimer et al., 1975; Suo \& Bower, 1994, 1995; Wong et al., 2003; Jin et al., 2009). In their approach, they considered that the wood-based panel is composed of many thin layers. They also considered that each thin layer has a uniform density profile. It became evident that the production of an OSB characterized by a flat VDP with different target densities was needed. To produce boards with a flat VDP through the thickness, a special pre-determined warm pre-pressing cycle was used (Wong et al., 1999, 2000; Jin et al., 2009; Ganev, 2004). The mats were pressed to the target densities at a relatively low plate temperature, and then the temperature of the platens was raised to reach the temperature required in the core to polymerize the adhesive.

The objective of this research was to determine unidirectional strand board (USB) mechanical properties as a function of density and moisture content. These properties are needed to model the hygromechanical behaviour of the OSB panel used in the engineered wood flooring manufacture (Barbuta et al. 2012). The mechanical properties determined were: parallel, perpendicular and through-the-thickness elastic modulus and parallel and perpendicular interlaminar shear moduli.

\section{Materials and Methods}

A mixture of trembling aspen $(90 \%)$ and white birch $(10 \%)$ strands was used in the manufacture of the experimental panels. The strands were provided by Produits Forestiers Arbec - OSB Division, located in Saint-Georges-de-Champlain, Quebec, Canada. The average strand sizes were $0.7 \mathrm{~mm}$ in thickness, $120 \mathrm{~mm}$ in length and $45 \mathrm{~mm}$ in width. The strands were dried to a moisture content of $2 \pm 0.5 \%$ based on oven-dry weight. The adhesive was liquid phenol-formaldehyde (PF) resin with 57\% solid contents. The strands were blended with $6.5 \%$ resin, $1.5 \%$ wax and water in a drum blender. After blending, the strand MCs ranged from 6.0 to $6.5 \%$. The $\mathrm{MC}$ was controlled by varying the amount of water added during blending. Unidirectional mats were formed by dropping the strands through a mesh with vertically adjustable parallel plates. The USB panels with a flat vertical density profile were manufactured in a Dieffenbacher laboratory press controlled by a PressMan system. This system allows for monitoring mat pressure and thickness, gas pressure and core temperature.

Three target densities were selected: 550,700 and $850 \mathrm{~kg} / \mathrm{m}^{3}$. The nominal thickness was $10.5 \mathrm{~mm}$ for all panels. A flat density profile through panel thickness was achieved by closing the press at a relatively low temperature $\left(100^{\circ} \mathrm{C}\right)$. Once the nominal thickness was achieved, the platen temperature was raised to $165^{\circ} \mathrm{C}$ until the core temperature reached $140^{\circ} \mathrm{C}$. A press closing temperature of $100^{\circ} \mathrm{C}$ was chosen to reduce the total press time, which ranged from $11 \mathrm{~min}$ and $30 \mathrm{~s}$ to $12 \mathrm{~min}$ and $30 \mathrm{~s}$ depending on panel density. These parameters were determined from the literature and preliminary tests. A total of 30 panels were manufactured.

After pressing, the panels were trimmed from $610 \mathrm{~mm}$ by $610 \mathrm{~mm}$ to $508 \mathrm{~mm}$ by $508 \mathrm{~mm}$ to remove the low-density edges. The manufacturing parameters are presented in Table 1. In order to eliminate eventual density peaks in the surface, the panels were sanded to a final thickness of $9 \mathrm{~mm}$. Relative to the target densities, the average panel densities after pressing were: 520,658 and $818 \mathrm{~kg} / \mathrm{m}^{3}$ respectively. The physical and mechanical properties were determined for each density and for two humidity levels: $20 \%$ and $50 \% \mathrm{RH}$ at $20{ }^{\circ} \mathrm{C}$. The specimens were conditioned to equilibrium moisture content (EMC) (less than $0.05 \%$ weight variation within $24 \mathrm{~h}$ ). The parallel and perpendicular elastic modulus $\left(\mathrm{E}_{1}\right.$ and $\left.\mathrm{E}_{2}\right)$, and the parallel and perpendicular interlaminar shear modulus $\left(\mathrm{G}_{13}\right.$ and $\left.\mathrm{G}_{23}\right)$ were determined in accordance with ASTM Standard D 1037-06a (ASTM International 2006). The test protocol for the tensile elastic modulus through panel thickness $\left(E_{3}\right)$ was inspired by ASTM Standard D 1037-06a (ASTM International, 2006). Strain was measured with a 5-mm MTS extensometer (Model 632.29F-30) placed directly on the specimen (Figure 1). The grain direction in the panel determined the direction of physical and mechanical properties.

An analysis of variance (ANOVA) was performed on the variables under study using the Statistical Analysis System (SAS) 9.1 software. The variables used were actual panel densities corresponded to the target densities $\left(550,700\right.$ and $\left.850 \mathrm{~kg} / \mathrm{m}^{3}\right)$ and $\mathrm{RH}(20 \%$ and $50 \%)$. Four replications of this experiment were performed for each property studied. 


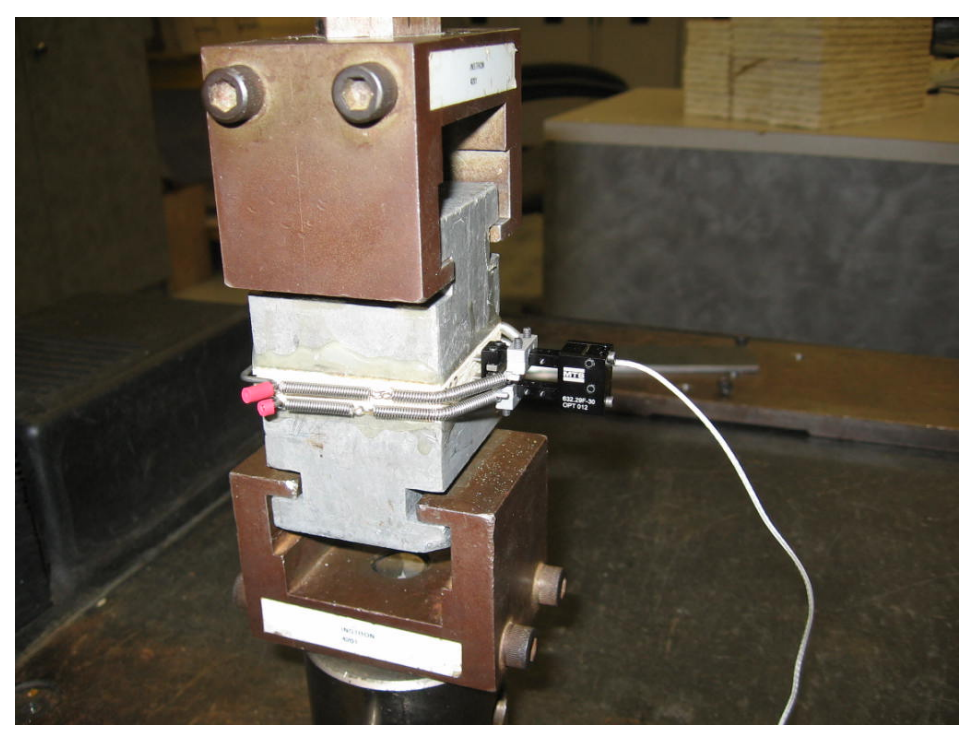

Figure 1. Setup for determination of tensile modulus of elasticity in the thickness direction $\left(\mathrm{E}_{3}\right)$

\section{Results and Discussion}

The results of the mechanical tests on the USB panels with a flat density profile are summarized in Table 1 . The values obtained for the elastic properties showed that the USB panel was a highly anisotropic material. This is in agreement with the results of Bucur et al. (1998), who found that OSB proved more anisotropic than medium-density fibreboard (MDF) and particleboard. As in solid wood, the highest value of the MOE was obtained in the longitudinal direction. Due to the structure of USB, the lowest value of the MOE was obtained in the thickness direction $\left(E_{3}\right)$. For the same reason, the values of interlaminar shear modulus $\left(\mathrm{G}_{13}\right.$ and $\left.\mathrm{G}_{23}\right)$ were lower than those of most solid woods (Katz et al., 2008). According to Cai and Ross (2010) the adhesive bond between wood strands resists slipping and often controls panel stiffness. The average values of interlaminar shear modulus, $\mathrm{G}_{13}$ and $\mathrm{G}_{23}$, were comparable to other published values of shear modulus in the major and minor axes of the OSB panel, which are typically in the range of 51 to $200 \mathrm{MPa}$ (Shrestha, 1999; Karacabeyli et al., 1996; Thomas, 2004). From the results shown in Table 1, it can be seen that the values obtained from the mechanical tests are influenced by density and RH. As expected, elastic properties increased as density increased and generally decreased as RH increased.

The results of the ANOVA for the impact of density and RH on the mechanical properties of USB panels with a flat density profile are presented in Table 2. Because there were differences between target and actual specimen densities (Table 1), the mean real density of the specimens at $50 \% \mathrm{RH}$ and $20^{\circ} \mathrm{C}$ was used in the statistical analysis, which showed that density had a significant effect on all the mechanical properties investigated (Table 2). The resulting F-values indicated a relationship at a $0.01 \%$ probability level between all mechanical properties and density. Panel density is a critical parameter that affects positively the properties of OSB panels. Several studies have investigated its effect on OSB properties (Lee \& Stephens, 1988, Brochmann et al., 2004; Sumardi et al., 2007; Chen et al., 2009; Grandmont et al., 2010). They all demonstrated a strong relationship between OSB density and mechanical properties. For the same material used in OSB manufacture, the improvement of the properties with increasing panel density can be explained by the compaction ratio. The higher the density, the greater the compaction. A higher compaction ratio promotes better between-strand contact, improved adhesive bonding and more desirable panel properties.

The ANOVA also showed that the effect of RH on MOE in all three directions and on the two shear moduli was not significant. Furthermore, the effect of the interaction between density and RH had no significant effect either. Generally, increasing RH and, indirectly, panel MC weakened mechanical properties. In this study, a trend may have been observed, but the differences between means were not significant. It seemed that the presence of the adhesive and the wax as well as thermal modification resulting from the pressing process reduced the effect of $\mathrm{RH}$ on mechanical properties. These results are somehow in agreement with the observations of Tang and Lee (1999), which investigated the effect of RH on the tensile strength and stiffness of three types of wood composite boards (randomly-oriented flakeboard, veneer-faced composite board and 4-ply plywood). The effect of MC on 
the tensile stiffness of all wood composite boards was found to be small when tested at low RH (35\% and 55\%) but it increased substantially when the panels were tested at high RH (75\% and 95\%) and in a water-soaked condition.

Table 1. Summary of USB mechanical properties

\begin{tabular}{|c|c|c|c|c|c|c|c|c|c|c|c|c|}
\hline $\begin{array}{l}\text { Target } \\
\text { density }\end{array}$ & RH & Statistic & E & & $\mathrm{E}_{2}$ & & $\mathrm{E}$ & & \multicolumn{2}{|c|}{$\mathrm{G}_{13}$} & \multicolumn{2}{|c|}{$\mathrm{G}_{23}$} \\
\hline \multirow[t]{5}{*}{$\mathrm{kg} / \mathrm{m}^{3}$} & \multirow[t]{5}{*}{$\%$} & & Actual & & Actual & & Actual & & Actual & & Actual & \\
\hline & & & density & & density & & density & & density & & density & \\
\hline & & & at $50 \%$ & & at $50 \%$ & & at $50 \%$ & & at $50 \%$ & & at $50 \%$ & \\
\hline & & & $\mathrm{RH}$ & Value & RH & Value & $\mathrm{RH}$ & Value & $\mathrm{RH}$ & Value & RH & Value \\
\hline & & & $\mathrm{kg} / \mathrm{m}^{3}$ & $\mathrm{MPa}$ & $\mathrm{kg} / \mathrm{m}^{3}$ & $\mathrm{MPa}$ & $\mathrm{kg} / \mathrm{m}^{3}$ & $\mathrm{MPa}$ & $\mathrm{kg} / \mathrm{m}^{3}$ & $\mathrm{MPa}$ & $\mathrm{kg} / \mathrm{m}^{3}$ & $\mathrm{MPa}$ \\
\hline & 20 & avg & 539 & 7512 & 569 & 994 & 543 & 102 & 551 & 179 & 544 & 95 \\
\hline 550 & 20 & std & 16,8 & 661,0 & 35,2 & 172,8 & 8,8 & 8,9 & 26,4 & 24,2 & 26,6 & 10,4 \\
\hline 550 & 50 & avg & 562 & 7350 & 571 & 1276 & 536 & 90 & 555 & 171 & 524 & 89 \\
\hline & 30 & std & 45,1 & 1665,3 & 28,4 & 269,9 & 9,4 & 13,9 & 22,0 & 24,7 & 9,4 & 13,4 \\
\hline & 20 & avg & 701 & 10971 & 735 & 2165 & 684 & 155 & 713 & 230 & 678 & 137 \\
\hline 700 & 20 & std & 33,7 & 1462,4 & 25,7 & 179,0 & 15,4 & 17,7 & 18,3 & 22,6 & 8,1 & 15,7 \\
\hline 100 & 50 & avg & 712 & 10184 & 717 & 1783 & 669 & 135 & 696 & 227 & 654 & 107 \\
\hline & 50 & std & 45,7 & 298,4 & 32,6 & 156,2 & 23,0 & 14,6 & 14,6 & 15,1 & 24,4 & 4,7 \\
\hline & 20 & avg & 822 & 13293 & 863 & 2140 & 871 & 168 & 862 & 231 & 871 & 140 \\
\hline 850 & 20 & std & 45,5 & 1017,7 & 17,0 & 530,9 & 16,7 & 11,5 & 15,7 & 6,5 & 11,1 & 7,1 \\
\hline 850 & 50 & avg & 848 & 12964 & 856 & 2539 & 874 & 144 & 854 & 214 & 855 & 128 \\
\hline & 50 & std & 21,6 & 1388,8 & 24,4 & 81,3 & 29,7 & 5,0 & 16,4 & 14,5 & 19,5 & 5,0 \\
\hline
\end{tabular}

$\mathrm{RH}=$ Relative humidity; $E_{\mathrm{i}}=$ Elastic modulus in the i direction; $\mathrm{G}_{\mathrm{ij}}=$ Shear modulus in the ij plane

Table 2. Results of the analysis of variance (F-values) for the mechanical properties of unidirectional OSB panels

\begin{tabular}{llllll}
\hline Source of variation & $\mathrm{E}_{1}$ & $\mathrm{E}_{2}$ & $\mathrm{E}_{3}$ & $\mathrm{G}_{13}$ & $\mathrm{G}_{23}$ \\
& F-value & F-value & F-value & F-value & F-value \\
\hline Model & $25.68^{* *}$ & $17.65^{* *}$ & $15.76^{* *}$ & $67.76^{* *}$ & $17.67^{* *}$ \\
Error & - & - & - & - & - \\
Density & $74.63^{* *}$ & $52.38^{* *}$ & $39.59^{* *}$ & $201.64^{* *}$ & $43.65^{* *}$ \\
HR & $0.14^{\mathrm{NS}}$ & $0.08^{\mathrm{NS}}$ & $0.09^{\mathrm{NS}}$ & $0.92^{\mathrm{NS}}$ & $0.02^{\mathrm{NS}}$ \\
Density*HR & $0.01^{\mathrm{NS}}$ & $0.20^{\mathrm{NS}}$ & $0.66^{\mathrm{NS}}$ & $0.67^{\mathrm{NS}}$ & $0.14^{\mathrm{NS}}$ \\
\hline
\end{tabular}

$\mathrm{HR}$ = Relative humidity; Ei = elastic modulus in the i direction; $\mathrm{Gij}=$ shear modulus in the ij plane

$* *=$ Significant at 0.01 probability level

NS $=$ Not significant at 0.05 probability level

The SAS procedure PROC REG was used to generate regression coefficients between the density of the USB panels and their mechanical properties. To develop the regression equations, the linear and quadratic effects had to be tested (Table 3 ). These effects and the regression equations to predict mechanical properties as a function of density are presented in Table 3 and Figure 2. Except for $E_{1}$ and $E_{2}$, the quadratic regression was significant with a corresponding $\mathrm{p}$-value lower than 0.01 . The correlation coefficients $\mathrm{R}^{2}$ were between 0.63 and 0.77 , indicating a relatively clear relationship between the variables studied. These relationships are very useful in the modeling of the mechanical properties of OSB panels as a function of the vertical density profile. 
Table 3. Results of regression analysis

\begin{tabular}{llllll}
\hline Source of variation & $\mathrm{E}_{1}$ & $\mathrm{E}_{2}$ & $\mathrm{E}_{3}$ & $\mathrm{G}_{13}$ & $\mathrm{G}_{23}$ \\
& $\mathrm{~F}$-value & $\mathrm{F}$-value & F-value & F-value & F-value \\
\hline Model & $36.13^{* *}$ & $29.00^{* *}$ & $32.55^{* *}$ & $18.14^{* *}$ & $27.09^{* *}$ \\
Error & - & - & - & - & - \\
Density & $71.71^{* *}$ & $56.12^{* *}$ & $51.17^{* *}$ & $24.54^{* *}$ & $37.80^{* *}$ \\
Density*Density & $0.53^{\mathrm{NS}}$ & $1.88^{\mathrm{NS}}$ & $13.93^{* *}$ & $11.74^{* *}$ & $16.37^{* *}$ \\
\hline
\end{tabular}

$\mathrm{Ei}=$ Elastic modulus in the $\mathrm{i}$ direction; $\mathrm{Gij}=$ shear modulus in the ij plane

$* *=$ Significant at 0.01 probability level

$\mathrm{NS}=$ Not significant at 0.05 probability level

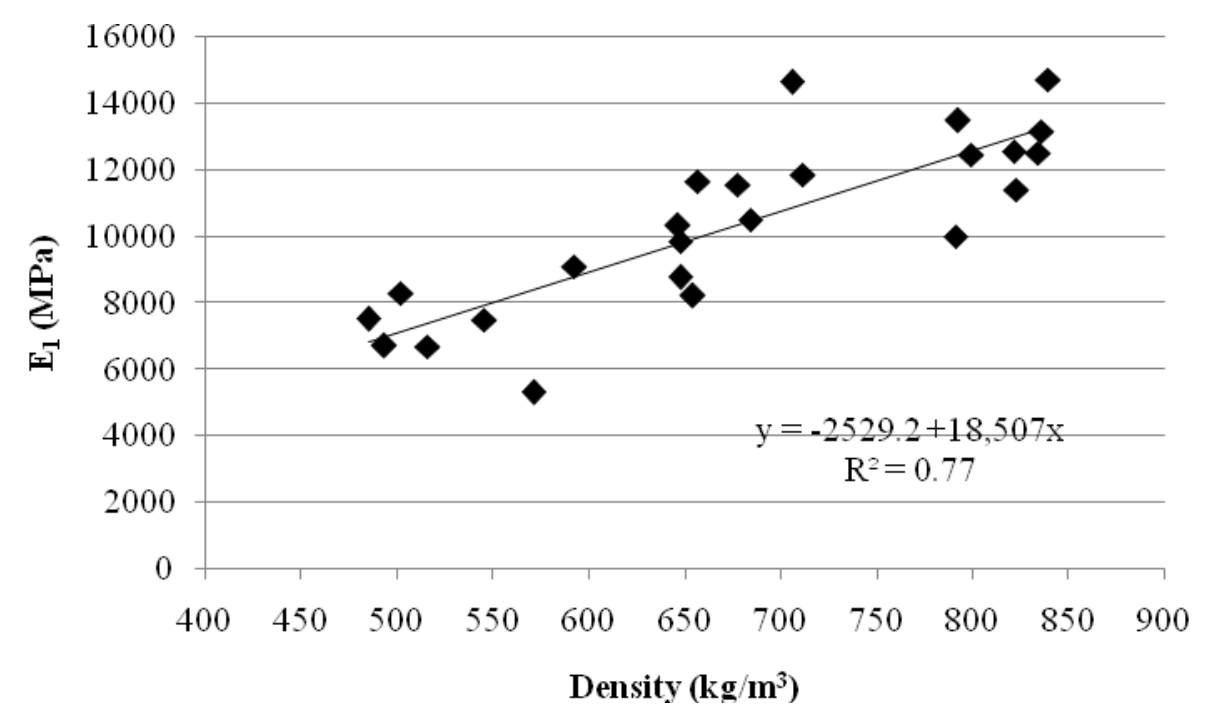

a)

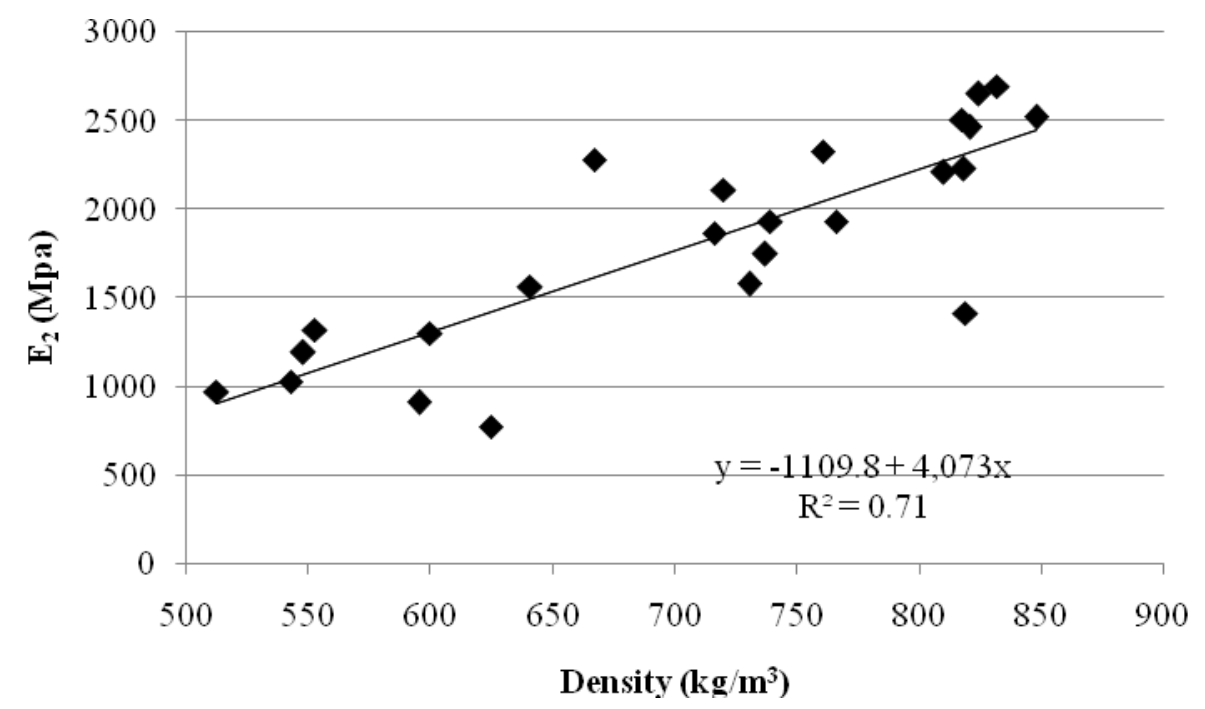

b) 

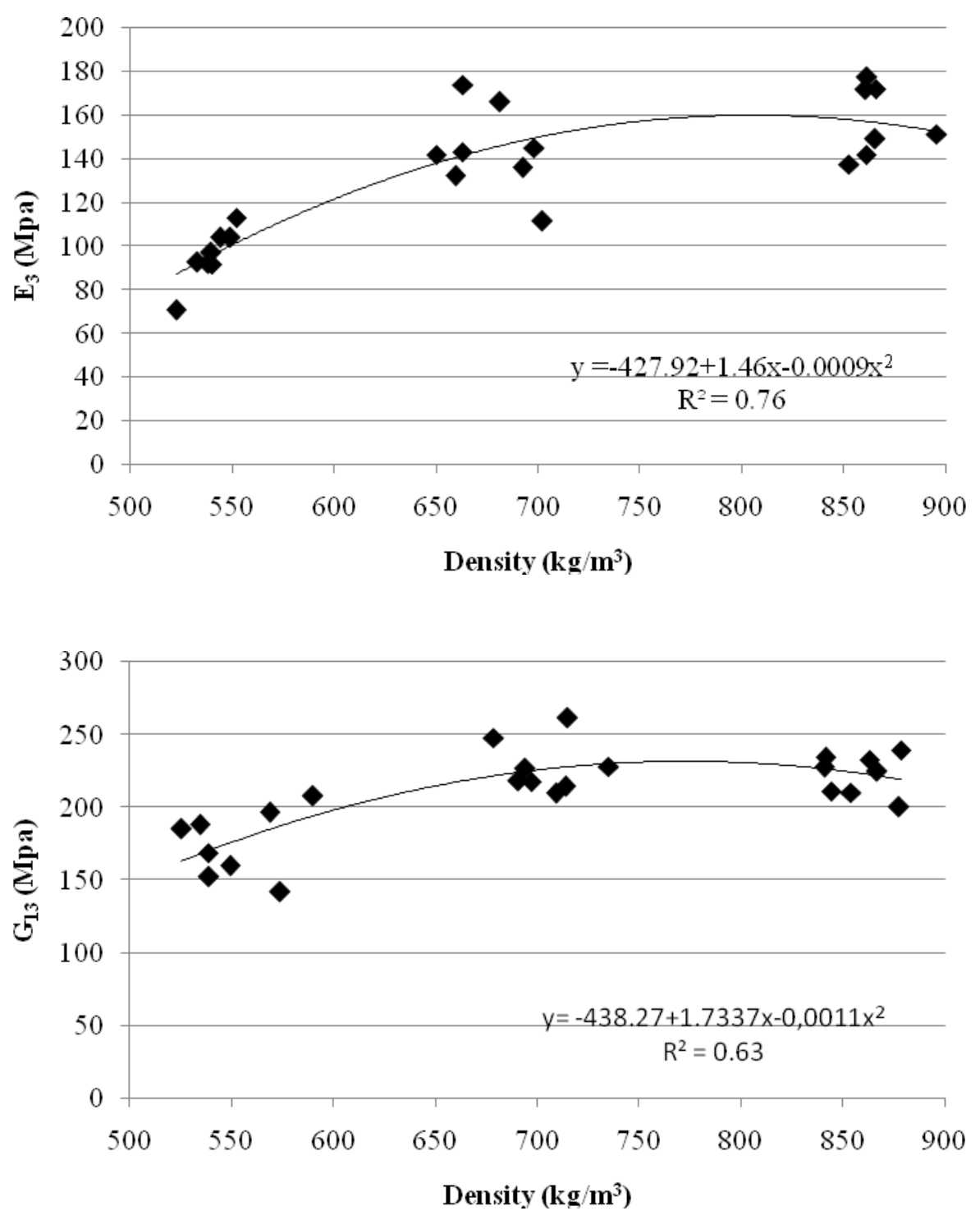

c)

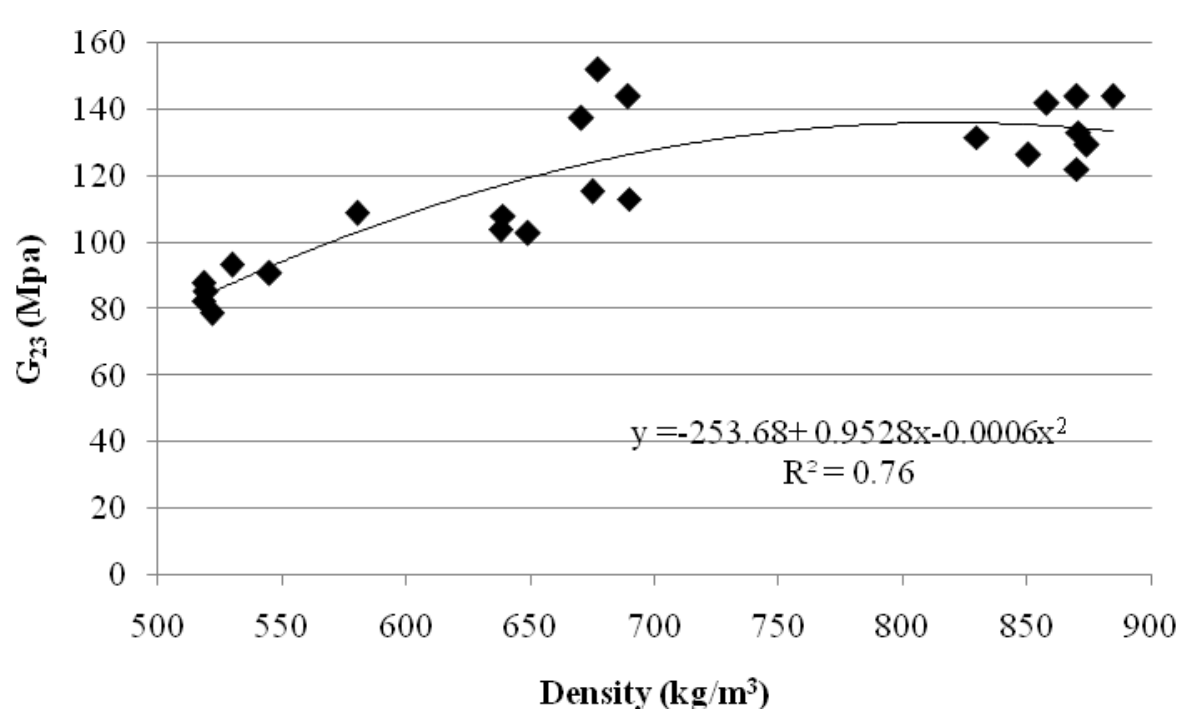

d)

e)

Figure 2. Effect of density on modulus of elasticity: a) $E_{1}$, b) $E_{2}$, c) $E_{3}$, and shear modulus: d) $G_{13}$, e) $G_{23}$ 


\section{Conclusions}

The purpose of this study was to determine critical mechanical properties of unidirectional strand board (USB), i.e.: $\mathrm{E}_{1}, \mathrm{E}_{2}, \mathrm{E}_{3}, \mathrm{G}_{13}$ and $\mathrm{G}_{23}$, as a function of density and moisture content. The results show that, for USB panels with a flat vertical density profile, and only density has a significant effect on these mechanical properties. For the densities considered (i.e.: 550, 700 and $850 \mathrm{~kg} / \mathrm{m}^{3}$ ), mechanical properties improved as panel density increased. Even though the effect of relative humidity $(\mathrm{RH})$ was not significant, a trend could be observed, suggesting that mechanical properties decreased with increasing RH. In view of USB variability, the correlation between density and the mechanical properties studied was good. The relationships obtained can be used to predict the mechanical properties of a standard oriented strand board (OSB) panel as a function of its vertical density profile. The results of this study provide a reliable measure of mechanical properties in OSB. These data will support the modeling of wood-based composites including OSB components (e.g.: EWF substrate, I-beam core), taking into account the variation of OSB mechanical properties as a function of density.

\section{References}

Andrews, C. K., Winistorfer, P. M., \& Bennett, R. M. (2001). The influence of furnish moisture content and press closure rate on the formation of the vertical density profile in oriented strandboard. For Prod. J., 51(5), 32-39.

ASTM International (2006). Standard methods of evaluating the properties of wood-based fiber and particle panel materials. Standard D, 1037-06a, 4.10, pp. 110-139. West Conshohocken, PA: American society of testing and materials.

Barbuta, C., Blanchet, P., Cloutier. A., Yadama, V., \& Lowell, E. (2010). Tailor made OSB for special application. Eur. J. Wood Prod., 69(4), 511-519. http://dx.doi.org/10.1007/s00107-010-0477-z

Blanchet, P. (2008). Contribution of engineered wood flooring components to its hygromechanical behaviour. Forest Prod. J., 58(7/8), 19-23.

Brochmann, J., Edwardson, C., \& Shmulsky, R. (2004). Influence of resin type and flake thickness on properties of OSB. Forest Prod. J., 54(3), 51-55.

Bucur, V., Ansell, M. P., Barlow, C. Y., Pritchard, J., Garros, S., \& Deglise, X. (1998). Physical methods for characterizing wood composites panel products. Holzforschung, 52, 553-561. http://dx.doi.org/10.1515/hfsg.1998.52.5.553

Cai, Z., \& Ross, R. J. (2010). Mechanical properties of wood-based composite materials. Wood handbook: wood as an engineering material: chapter 12. Gen. Tech. Rep., FPL-GTR-190, pp. 12.1-12.12. Madison, WI: U.S. Department of Agriculture.

Chen, S., Du, C., \& Wellwood, R. (2010). Effect of Panel Density on Major Properties of Oriented Strandboard. Wood Fiber Sci., 42(2), 177-184.

Ganev, S. (2004). Modelling the hygroscopic warping of OSB panels. Project No. 3643, p. 30. Québec, Canada: Forintek Canada Corp.

Geimer, R. L., Montrey, H. M., \& Lehmann, W. F. (1975). Effects of layer characteristics on the properties of three-layer particleboards. Forest Prod. J., 25(3), 19-29.

Grandmont, J.-F., Cloutier, A., Gendron, G., \& Desjardins R. (2010). Effect of density on the properties of oriented strandboard web stock used in wood I-joists. Wood Fiber Sci., 60(7/8), 592-598.

Hiziroglu, S. (2006). Oriented strandboard as a building material. (FAPC-145). Oklahoma, OK: Oklahoma State University. $\quad$ Retrieved http://pods.dasnr.okstate.edu/docushare/dsweb/Get/Document-3164/FAPC-145web.pdf

Jin, J., Dai, C., Hsu, W. E., \& Changming Y. (2009). Properties of strand boards with uniform and conventional vertical density profiles. Wood Sci. Technol, 43, 559-574. http://dx.doi.org/10.1007/s00226-009-0248-3

Karacabeyli, E., Lau, P., Henderson, C. R., Meakes, F. V., \& Deacon, W. (1996). Design rated oriented strandboard in CSA standards. Can J. Civil Eng., 23, 431-443. http://dx.doi.org/10.1139/196-047

Katz, J. L., Spencer, P., Wang, Y., Misra, A., Marangos, O., \& Friis, L. (2008). On the anisotropic elastic properties of woods. J Mater Sci., 43, 139-145. http://dx.doi.org/10.1007/s10853-007-2121-9

Kelly, M. W. (1977). Critical literature review of relationships between processing parameters and physical properties of particleboard. Research Note FPL-10, p. 65. Madison, WI: US Department of Agriculture. 
Lee, A. W. C., \& Stephens, C. B. (1988). Comparative shear strength of seven types of wood composite panels at high and medium relative humidity conditions. Forest Prod J., 30(3), 49-52.

Lee, J. N., Kamke, F. A., \& Watson, L. T. (2007). Simulation of the hot pressing of a multi- layered wood strand composite. J. Composite Materials, 41, 879-904. http://dx.doi.org/10.1177/0021998306067071

Shrestha, D. (1999). Shear properties tests of oriented strandboard panels. For Prod. J., 49(10), 41-46.

Sumardi, .I, Ono, K., \& Susuki, S. (2007). Effect of board density and layer structure on the mechanical properties of bamboo oriented strandboard. $J$ Wood Sci., 53, 510-515. http://dx.doi.org/10.1007/s10086-007-0893-9

Suo, S., \& Bowyer, J. (1994). Simulation modeling of particleboard density profile. Wood Fiber Sci., 26(3), 397-411.

Suo, S., \& Bowyer, J. (1995). Modeling of strength properties of structural particleboard. Wood Fiber Sci., 27(1), 84-94.

Tang, R. C., \& Lee, J. N. (1999). Tensile properties of wood composite boards: Effect of relative humidity. Proc. Pacific Timber Engineering Conference, 14-18 March. Rotorua, New Zealand: Walford, G. B. \& Gaunt, D. J.

Thomas, W. H. (2004). Planar shear moduli of rigidity of an oriented strand board from bending and shear tests. Mater Struc., 37, 480-484.

Wang, S., \& Winistorfer, P. M. (2000). Effect of species and its distribution on the layer characteristics of OSB. Forest Prod J., 50(4), 37-44.

Wong, E. D., Yang, P., Zhang, M., Wang, Q., Nakao, T., Li, K. F., \& Kawai, S. (2003). Analysis of the effects of density profile on the bending properties of particleboard using finite element method (FEM). Holz als Roh-und Werkstoff 61: 66-72. http://dx.doi.org/10.1007/s00107-002-0350-9

Wong, E. D., Zhang, M., Wang, Q., \& Kawai, S. (1999). Formation of the density profile and its effects on the properties of particleboard. Wood Sci. Technol, 33, 327-340. http://dx.doi.org/10.1007/s002260050119

Wong, E. D., Zhang, M., Wang, Q., Han, G., \& Kawai, S. (2000). Formation of the density profile and its effects on the properties of fiberboard. J Wood Sci., 46,202-209. http://dx.doi.org/10.1007/BF00776450

Xu, W., \& Winistorfer, P. M. (1996). Fitting an equation to vertical density profile data using Fourier analysis. Holz als Roh-und Werkstoff 54: 57-59. http://dx.doi.org/10.1007/s001070050134 